\title{
Implementasi Konsep Overlay Network pada Greedy Perimeter Stateless Routing (GPSR) di VANETs
}

\author{
Kevin Arditya, Supeno Djanali, dan Radityo Anggoro \\ Departemen Teknik Informatika, Fakultas Teknologi Informasi \\ Institut Teknologi Sepuluh Nopember (ITS) \\ e-mail:supeno@if.its.ac.id
}

\begin{abstract}
Abstrak-Vehicular Ad hoc Network (VANETs) adalah teknologi komunikasi yang menggunakan jaringan ad hoc untuk berkomunikasi. Pengembangan VANETs berfokus kepada routing protocol yang dinamis yang dapat bertahan pada lingkungan VANETs yang cepat dan tidak terprediksi. Greedy Perimeter Stateless Routing (GPSR) merupakan salah satu protokol dalam VANETs yang bekerja secara geographic. Pengiriman paket data dilakukan secara greedy berdasarkan posisi node tetangga menuju node destination. Oleh karena itu, dibutuhkan proses route discovery agar GPSR bisa mendeteksi ketersediaan rute menuju node destination. GODV adalah modifikasi dari GPSR yang mengadopsi proses route discovery pada Dynamic Source Routing (DSR). Sebelum melakukan pengiriman paket data, node sumber mengirimkan paket route request menuju node destination. Lalu node destination akan merespon dengan mengirimkan paket route reply kembali node sumber dengan menyimpan titik-titik rute pengiriman paket data yang digunakan sebagai implementasi konsep overlay network. Hasil pengujian yang dilakukan menunjukkan bahwa GODV memberikan nilai rata-rata packet delivery ratio (PDR) yang lebih baik dibandingkan dengan GPSR dengan kenaikan PDR sebesar $16 \%$.
\end{abstract}

Kata Kunci-Overlay Network, GPSR, DSR, VANETs.

\section{PENDAHULUAN}

$S_{\mathrm{k}}^{\mathrm{e}}$ makin pesatnya perkembangan teknologi, aspek komunikasi antar komputer menjadi sangat penting. Salah satu cara komputer berkomunikasi adalah menggunakan jaringan ad hoc. Dalam jaringan ad hoc setiap komputer terkoneksi satu sama lain secara langsung tanpa bergantung pada router atau access point. Salah satu system yang menggunakan jaringan ad hoc adalah VANETs.

VANETs merupakan pengembangan dari Mobile Ad Hoc Network (MANET) yang diapkikasikan dalam kendaraan. Jaringan VANETs memungkinkan kendaraan saling berkomunikasi tanpa membutuhkan pengaturan infrastruktur tersentral ataupun server yang digunakan untuk mengontrol kerjanya. VANETs memiliki banyak routing protocol, salah satunya adalah Greedy Perimeter Stateless Routing (GPSR) yang akan digunakan nantinya.

Greedy Perimeter Stateless Protocol (GPSR) menggunakan posisi node secara geographic untuk mengetahui posisi destination. Untuk forwarding paketnya GPSR akan mencari node mana yang paling dekat dengan destination secara greedy tanpa tahu apakah node tersebut benar-benar bisa digunakan untuk mengirimkan paket. Oleh karena itu, performa GPSR perlu ditingkatkan dengan cara menambahkan metode route discovery yang akan digunakan untuk mencari rute menuju destination.

Greedy Perimeter Stateless Routing (GPSR) akan dimodifikasi dengan metode route discovery protokol DSR dan menerapkan konsep overlay network yang diberi nama GODV. Uji coba akan dilakukan dan akan membandingkan performa protokol GPSR dan GODV dengan skenario grid dengan beberapa variasi node.

\section{ANALISIS DAN PERANCANGAN}

\section{A. Vehicular Ad-Hoc Network (VANETs)}

Vehicular Ad hoc Network merupakan bentuk dari jaringan nirkabel yang bersifat ad hoc dan merupakan pengembangan dari Mobile Ad hoc Network (MANET) yang mempertimbangkan semua kendaraan di dalam jaringan sebagai node yang digunakan untuk berkomunikasi dengan kendaraan lainnya pada cakupan tertentu. Pada MANET maupun VANETs, node yang bergerak bergantung pada ad hoc routing protocol untuk menentukan bagaimana cara mengirimkan pesan dari source node menuju destination node. Ad hoc routing protocol dapat diklasifikasikan menjadi dua kategori, yaitu Topology-Based Routing dan Geographic Position-Based Routing. Meskipun menggunakan routing protocol yang sama, VANETs memiliki perbedaan karakteristik dengan MANET. Pergerakan pada VANETs dibatasi oleh bentuk jalan yang dilalui kendaraan dan kecepatan kendaraan yang cenderung lebih cepat.Terdapat dua jenis node yang tergabung pada VANETs, yaitu Road-side Unit (RSU) dan On-board Unit (OBU). -lain. OBU merupakan kendaraan yang berjalan pada suatu bidang jalan. 


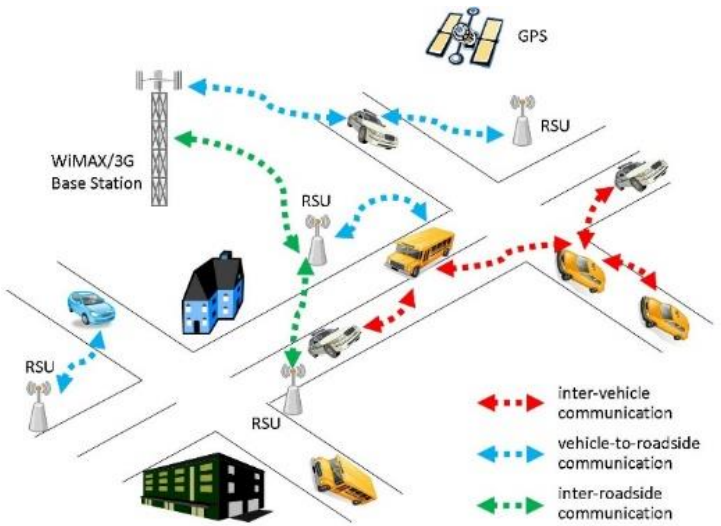

Gambar 1. Ilustrasi VANET [1]

RSU merupakan node yang terpasang pada bagian jalan yang terhubung dengan jaringan backbone untuk memberikan informasi-informasi penting kepada OBU. lalu lintas, dan lain Informasi yang dapat diberikan oleh RSU adalah batas kecepatan, status lampu Informasi yang dapat diberikan oleh OBU antara lain adalah kecepatan, lampu sen, status rem, sudut kemudi, dan kondisi lalu lintas. Ada dua tipe komunikasi yang ada dalam VANETs, yaitu antara kendaraan (yang memiliki OBU) dengan kendaraan yang lain dan antara kendaraan dengan RSU. Ilustrasi mengenani komunikasi dalam VANETs dapat dilihat pada Gambar 1.[1]

\section{B. Greedy Parameter Stateless Routing (GPSR)}

Greedy Perimeter Stateless Routing merupakan Geographical Routing Protocol yang menggunakan positionbased routing, di mana setiap node saling mengetahui posisi sendiri dan posisi tetangga terdekatnya. Routing protocol GPSR akan mengirimkan hello message secara berkala untuk memperbarui informasi lokasi geografis node yang msaih berada pada jangkauan transmisi. GPSR menggunakan dua metode untuk melakukan pengiriman paket data, yaitu Greedy Perimeter dan Perimeter Forwarding. [2]

\section{Dynamic Source Routing (DSR)}

Dynamic Source Routing merupakan routing protocol yang bersifat reactive yang artinya protokol ini akan melakukan route discovery jika sebuah node inisiator ingin berkomunikasi dengan node yang lain, oleh karena itu network traffic dapat diturunkan. Sebelum melakukan pengiriman paket data, DSR akan melakukan route discovery kemudian menyimpan route path pada header paket yang digunakan untuk pengiriman paket data. Pada DSR, intermediate node tidak perlu mengurus informasi routing. Mekanisme route discovery dapat dilihat pada Gambar 2. Proses route discovery di mulai saat sebuah node source ingin berkomunikasi dengan node destination. Node source akan mengirim route request (RREQ) menuju node destination. Node intermediate akan menyisipkan dirinya pada route path yang ada pada header RREQ jika belum pernah menerima RREQ tersebut dan menyimpan nomor RREQ pada routing table, lalu node tersebut akan melakukan broadcast ulang ke node yang lain. Apabila pada routing table node sudah ada nomor RREQ tersebut maka paket RREQ akan di drop. [3]

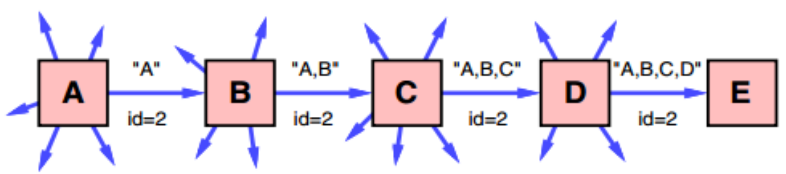

Gambar 2. Mekanisme route discovery pada DSR [3]

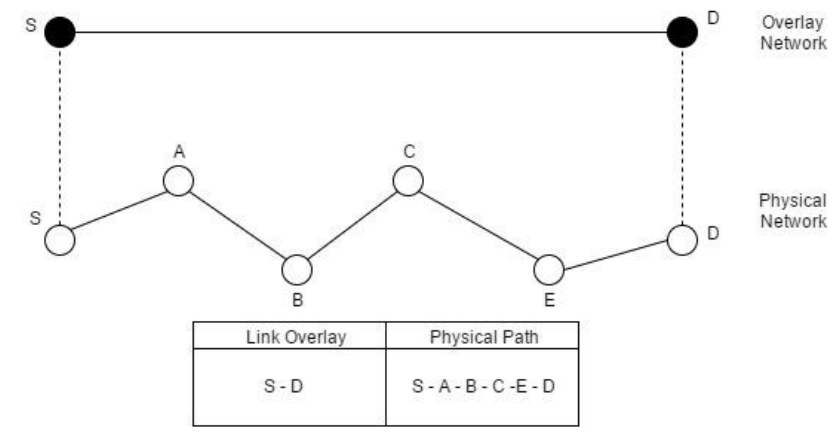

Gambar 3. Ilustrasi konsep overlay network

\section{Overlay Network}

Overlay Network adalah suatu jaringan yang dibangun di atas jaringan lain, yang artinya setiap node saling terhubung melalui jaringan virtual di atas jaringan fisik. Konsep overlay network digunakan pada proses pengiriman paket data. Node source secara langsung mengirimkan paket data menuju node destination pada overlay network, namun jika lihat dari physical network pengiriman paket data melalui node-node tetangga. Ilustrasi mengenai konsep overlay network dapat dilihat pada Gambar 3. [4]

\section{E. $G O D V$}

GODV merupakan modifikasi dari protokol GPSR dengan menambahkan proses route discovery dari protokol DSR. Pada GPSR proses pengiriman paket data dilakukan dengan mencari node yang terdekat dengan node tujuan tanpa mengetahui ketersedian jalan menuju node tujuan. Node yang paling dekat dengan tujuan belum tentu memiliki jalan menuju node tujuan.

Pada GODV proses pengiriman paket data dimulai dengan mencari ketersedian rute menuju node tujuan. Dengan menggunakan proses route discovery node sumber akan mengetahui rute yang harus digunakan dalam proses pengiriman paket data. Rute yang telah didapatkan merupakan rute yang akan selalu digunakan oleh node sumber untuk mengirimkan paket data menuju node tujuan yang sama.

Node sumber akan mengirimkan paket route request menuju node tujuan untuk mencari rute pengiriman paket. Node tetangga yang menerima paket route request akan mengirimkan ulang paket route request apabila node tetangga belum pernah menerima paket route request tersebut. Apabila node tetangga sudah pernah menerima paket route request maka paket tersebut akan langsung di drop. Node tujuan akan merespon paket route request dengan mengirimkan paket route reply menuju node sumber.

Node tetangga yang menerima paket route reply akan membandingkan posisinya dengan posisi node sebelumnya. Apabila ada perbedaan posisi berdasarkan sumbu x dan y, maka posisi node tersebut dan node sebelumnya akan disimpan pada header route reply. Ilustrasi mengenai protokol GODV dapat dilihat pada Gambar 4. 

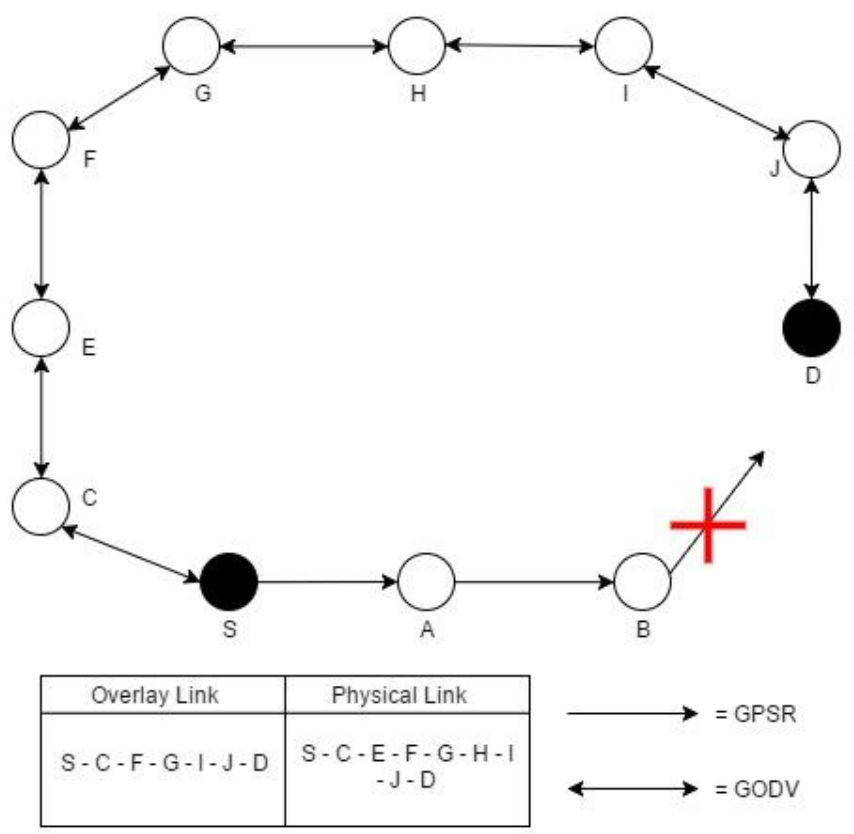

Gambar 4. Ilustrasi protokol GODV

\section{UJI COBA}

Uji coba menggunakan skenario grid dengan kecepatan 20 $\mathrm{m} / \mathrm{s}$ dengan menggunakan variasi node 25, 50, 75 dan 100 node. Protokol yang digunakan untuk uji coba adalah GPSR dan GODV. Dari hasil uji coba yang dilakukan akan dibandingkan nilai packet delivery ratio (PDR), end to end delay serta routing overhead (RO) dari protokol GPSR dan protokol GODV.

Berdasarkan grafik yang ditunjukkan Gambar 5, nilai packet delivery ratio untuk protokol GODV lebih tinggi jika dibandingkan dengan protokol GPSR. Nilai PDR pada GODV bisa lebih tinggi karena adanya rute pengiriman paket data yang dihasilkan dari proses route discovery. Rute yang dihasilkan dari proses route discovery memang berbeda dengan rute pengiriman paket data oleh protokol GPSR yang menggunakan metode greedy forwarding secara langsung.

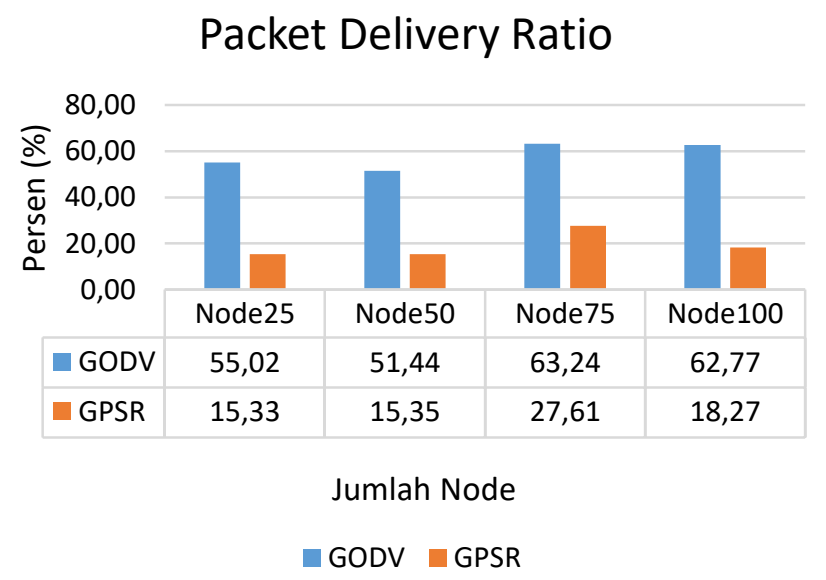

Gambar 5. Grafik nilai packet delivery ratio

\section{End to End Delay}

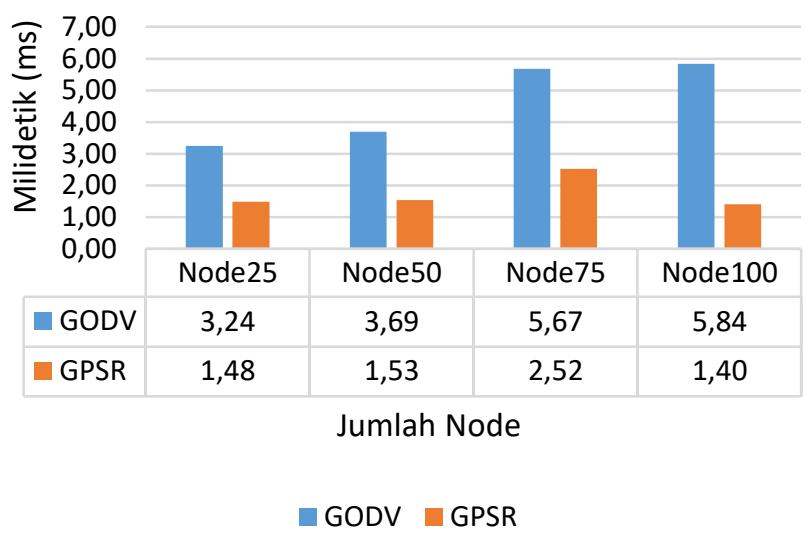

Gambar 6. Grafik nilai end to end delay

Berdasarkan grafik yang ditunjukkan Gambar 6, nilai end to end delay pada protokol GODV lebih tinggi jika dibandingkan dengan protokol GPSR. Nilai end to end delay pada protokol GODV bisa lebih tinggi karena rute yang dihasilkan dari proses route discovery lebih jauh jika dibandingkan dengan rute pengiriman paket data pada protokol GPSR. Ilustrasi mengapa nilai end to end delay pada protokol GODV bisa lebih tinggi dapat dilihat pada Gambar 4.

Berdasarkan grafik yang ditunjukkan Gambar 7, nilai routing overhead pada protokol GODV lebih kecil jika dibandingkan dengan protokol GPSR. Nilai routing overhead pada protokol GODV bisa lebih kecil karena adanya rute pengiriman paket data yang dihasilkan proses route discovery. Rute pengiriman paket data pada protokol GODV meningkatkan nilai packet delivery ratio yang berdampak pada turunnya nilai routing overhead protokol GODV. Nilai routing overhead dipengaruhi oleh banyaknya paket data yang terkirim.

\section{Routing Overhead}

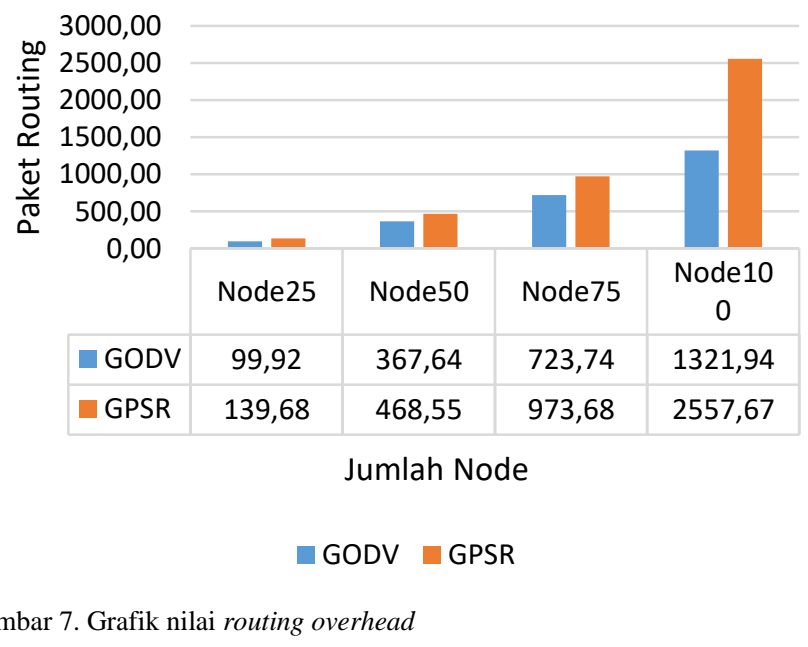




\section{KESIMPULAN DAN SARAN}

Setelah melakukan pengujian dan evaluasi, didapatkan kesimpulan sebagai berikut:

1. Packet Delivery Ratio (PDR) menunjukkan bahwa pada, protokol GODV lebih baik dibandingkan dengan protokol GPSR. Berdasarkan hasil uji coba, rata-rata nilai PDR untuk protokol GODV adalah $52.69 \%$ sedangkan rata-rata nilai PDR untuk protokol GPSR adalah $22.73 \%$.

2. End to end delay pada protokol GODV lebih tinggi dibandingkan dengan end to end delay protokol GPSR, hal ini dikarenakan rute perjalanan yang dihasilkan dari route discovery tidak selalu rute yang tercepat. Berdasarkan hasil uji coba, rata-rata nilai end to end delay untuk protokol GODV adalah $4.24 \mathrm{~ms}$ dan rata-rata nilai end to end delay untuk protokol GPSR adalah $1.96 \mathrm{~ms}$.

3. Routing Overhead pada protokol GODV lebih baik daripada routing overhead protokol GPSR karena kesuksesan pengiriman paket data lebih baik pada protokol GODV. Berdasarkan hasil uji coba, rata-rata nilai routing overhead untuk protokol GODV adalah 604.63 paket, sedangkan untuk protokol GPSR adalah 889.41 paket.

4. Implementasi route discovery dan konsep overlay network dapat meningkatkan rasio kesuksesan pengiriman paket data pada VANETs yang menyebabkan turunnya nilai routing overhead, namun nilai end to end delay akan meningkat.

5. Rute yang didapatkan dari proses route discovery belum tentu rute yang terbaik karena akan ada kondisi di mana rute yang didapatkan tidak terdapat node untuk melakukan pengiriman paket data.

Adapun saran-saran yang diberikan untuk pengembangan sistem ini kedepannya adalah sebagai berikut:

1. Pada saat melakukan perbandingan antara dua posisi node pada paket RREP dapat ditambahkan perhitungan untuk mengetahui lebih spesifik apakah dua buah node berada pada bidang jalan yang berbeda.

2. Pada node inisiator dapat di implementasikan rute perjalanan menuju lebih dari satu destination.

3. Maintenance rute perjalanan dapat ditambahkan untuk melakukan route discovery ulang apabila node source dan destination dinamis.

\section{DAFTAR PUSTAKA}

[1] S. P. A. Sharma, "Node Selection Algorithm for Routing Protocols in VANET," nternational J. Adv. Sci. Technol., vol. 96, pp. 43-54, 2016.

[2] N. T. Silmi, Modifikasi Protokol GPSR-MV dalam Pemilihan Forwarding Node pada VANET. 2016.

[3] P. A. R. P. S. P. N. Patel, "A Survey Paper on Dynamic Source Routing Protocol (DSR) in Ad-Hoc Network," Int. J. Sci. Res. Dev. IJSRD, vol. 2, no. 10, pp. 43-45, 2014.

[4] J. G.-J. a. A. Gazo-Cervero, "Overview and Challenges of Overlay Network: A Survey,” Int. J. Comput. Sci. Eng. Surv., vol. 2, no. 1, pp. 19-37, 2011. 